\title{
Interaction of chorioamnionitis at term with maternal, fetal and obstetrical factors as predictors of neonatal mortality: a population-based cohort study
}

Dina Zaki ${ }^{1}$, Jaques Balayla ${ }^{2}$, Marc Beltempo ${ }^{3}$, Guillaume Gazil ${ }^{4}$, Anne Monique Nuyt ${ }^{5,6}$ and Isabelle Boucoiran ${ }^{1,6,7^{*}}$ (D)

\begin{abstract}
Background: Chorioamnionitis is a frequent complication of pregnancy and is known to be associated with serious adverse post-natal outcomes including death. However, the assessment of fetal well-being in labor in the context of chorioamnionitis is often challenging because of fetal tachycardia. Identifying specific risk factors for adverse neonatal outcomes in the context of chorioamnionitis could therefore be of paramount importance. This study aimed to determine if maternal and fetal risk factors for increased neonatal mortality and early neonatal mortality are modified in the context of chorioamnionitis in term pregnancies.
\end{abstract}

Methods: A retrospective population-based cohort study using the United States birth/infant death public file from 2011 to 2013 was performed, including all live births at 37 weeks gestation and beyond. Interaction between chorioamnionitis and maternal demographic variables as well as labor and delivery potential risk factors were analyzed for association with neonatal death ( $<28$ days) and early neonatal death ( $<7$ days) using multivariate logistic regressions.

Results: Among 9,034,428 live births, the prevalence of chorioamionitis was 1.29\% (95\% Cl 1.28-1.30\%). The incidence of neonatal death and early neonatal death were 0.09 and $0.06 \%$ in the chorioamnionitis group versus 0.06 and $0.04 \%$ in the no chorioamnionitis group $(p=0.0003$ and $<0.0001)$, respectively. Smoking was significantly associated with neonatal death and early neonatal death in the context of chorioamnionitis (OR 2.44, Cl:1.34-4.43/ 2.36 Cl:1.11-5.01) but was either less strongly or not associated in the absence of chorioamnionitis (OR 1.24, Cl:1.14-1.35/0.93, Cl:0.821.05). The association between gestational age (37 weeks compared to 39 weeks) and neonatal death was more important in the context of chorioamnionitis $(\mathrm{OR}=3.19, \mathrm{Cl}: 1.75-5.82$ versus $1.63, \mathrm{Cl}: 1.49-1.79)$. Multivariate analysis identified the following risk factors for neonatal death and/or early neonatal death: low maternal education, extreme maternal age, obesity (BMI $>35 \mathrm{~kg} / \mathrm{m}^{2}$ ), late or no prenatal care, diabetes, meconium-stained amniotic fluid, gestational ages other than 39 weeks, neonatal weight $<2500 \mathrm{~g}$ and delivery by vacuum or caesarian.

(Continued on next page)

\footnotetext{
* Correspondence: isabelle.boucoiran@umontreal.ca

1 Department of Obstetrics and Gynecology, Faculty of Medicine, Université

de Montréal, 3175 Côte Sainte-Catherine, Montreal, QC H3T 1C5, Canada

${ }^{6} \mathrm{CHU}$ Sainte-Justine Research Centre, Montreal, QC, Canada

Full list of author information is available at the end of the article
}

(c) The Author(s). 2020 Open Access This article is licensed under a Creative Commons Attribution 4.0 International License, which permits use, sharing, adaptation, distribution and reproduction in any medium or format, as long as you give appropriate credit to the original author(s) and the source, provide a link to the Creative Commons licence, and indicate if changes were made. The images or other third party material in this article are included in the article's Creative Commons licence, unless indicated otherwise in a credit line to the material. If material is not included in the article's Creative Commons licence and your intended use is not permitted by statutory regulation or exceeds the permitted use, you will need to obtain permission directly from the copyright holder. To view a copy of this licence, visit http://creativecommons.org/licenses/by/4.0/ The Creative Commons Public Domain Dedication waiver (http://creativecommons.org/publicdomain/zero/1.0/) applies to the data made available in this article, unless otherwise stated in a credit line to the data. 
(Continued from previous page)

Conclusions: Smoking as well as early term have a positive interaction with chorioamnionitis for the risk of neonatal mortality. This should be taken into account when counseling pregnant women and managing laboring pregnant women with suspected chorioamnionitis.

Keywords: Neonatal death, Chorioamnionitis, Smoking, Early term

\section{Background}

Chorioamnionitis is a frequent complication of pregnancy and is known to be associated with serious maternal, fetal and long term-postnatal adverse outcomes including stillbirth, neonatal sepsis, chronic lung and brain neonatal diseases including hypoxic ischemic encephalopathy leading to long-term disabilities as well as maternal post-partum infections and sepsis [1].

Term delivery is associated with a lower complication rate than preterm delivery, yet the impact of chorioamnionitis in this population is less studied. Furthermore, the majority of term infants have less follow-up than their preterm counterparts however chorioamnionitis could be a risk factor requiring additional follow-up.

Chorioamnionitis is most often due to ascending bacteria causing acute inflammation of the membranes and the chorion of the placenta. Risk factors for chorioamnionitis include longer duration of membrane rupture (more than $12 \mathrm{~h}$ ), prolonged labor, nulliparity, internal monitoring of labor, multiple vaginal exams (more than or equal to 3), meconium-stained amniotic fluid, smoking, alcohol or drug abuse, immune compromised states and colonization with group B streptococcus. (1) The importance of clinical diagnosis in the pregnant woman has been underlined by its association with fetal and maternal mortality if left untreated [2]. Studies have shown that chorioamnionitis was associated with an approximately 2- and 3.5- fold increased odds of neonatal adverse outcomes $<34$ and $>34$ weeks respectively regardless of chorioamnionitis duration [3].

However, to our knowledge, no study has examined the effect specific maternal, fetal and obstetrical risk factors on neonatal mortality in the context of chorioamnionitis in term infants. Recognizing these risk factors could be an asset when tailoring protocols for the clinical management of chorioamnionitis. This study aimed to determine if maternal and fetal risk factors for increased neonatal mortality and early neonatal mortality are modified in the context of chorioamnionitis at term.

\section{Methods}

We performed a retrospective, population-based cohort study using the US Centers for Disease Control and Prevention (CDC) 2011-2013 linked birth/infant death public data set. This data is used for monitoring and exploring relationships between infant death and risk factors present at birth. It contains information on approximately 4 million annual live births in the United States (U.S.), and includes a number of obstetrical, perinatal and infant characteristics. The information from the death certificate is linked to information from the birth certificate for each infant under 1 year of age. This allows the US CDC to use many additional variables available from the birth certificate to conduct analyses of infant mortality patterns. This file is publicly available and does not contain any identification data (https://www.cdc.gov/nchs/nvss/linked-birth.htm).

All live births at 37 weeks or more were included. Multiple gestations and fetuses with severe congenital anomalies were excluded. These were determined using the CDC dictionary of congenital anomalies and include anencephaly, congenital hydrocephalus, spina bifida, other congenital malformations of the nervous, circulatory, respiratory, digestive, genitourinary and musculoskeletal systems.

The outcomes measured were (1) neonatal death defined as death in the first 28 days after live birth and (2) early neonatal death defined as infant death in first 7 days of life.

Chorioamnionitis was reported if documented on the birth record as "clinical chorioamnionitis". Detailed clinical criteria for the diagnosis of chorioamnionitis were not available. Other potential risk factors for neonatal death were identified based on literature review and availability in the US CDC public files. These maternal and fetal variables are outlined in Table 1.

\section{Statistical analysis}

Descriptive statistics were computed for all variables of interest. Results were grouped by chorioamnionitis status for each outcome (early death and total neonatal death). Odds ratios by chorioamnionitis status were also computed between each outcome and risk factor from the same model to explore their association and their interaction with chorioamnionitis. In addition, the potential effect of chorioamnionitis (and its importance) on these associations was evaluated graphically using interaction plots.

For modelling each outcome, intermediate multivariable logistic models were used with chorioamnionitis and each covariate as independent variables, as well as the interaction between them. To evaluate which variables would be a candidate for each final model, $p$-values from the aforementioned modelling were taken into account. Variables and interaction factors with a p-value 
Table 1 Demographics and Characteristics of Mothers and Babies Stratified by Chorioamnionitis - n\%

\begin{tabular}{|c|c|c|c|c|c|}
\hline Characteristic & $\begin{array}{l}\text { Total } \\
(\boldsymbol{N}=9,034,428)\end{array}$ & $\begin{array}{l}\text { Chorioamnionitis } \\
(\boldsymbol{N}=116,627)\end{array}$ & No chorioamnionitis $(\boldsymbol{N}=8,917,801)$ & $\boldsymbol{p}$-Value & Unknown \\
\hline Neonatal Death & $5794(0.1)$ & $106(0.1)$ & $5688(0.1)$ & 0.0003 & \\
\hline Early Death & $3391(0.0)$ & $71(0.1)$ & $3320(0.0)$ & $<0.001$ & \\
\hline Late Death & $2403(0.0)$ & $35(0.0)$ & $2368(0.0)$ & 0.4720 & \\
\hline Admission to NICU & $339,942(3.8)$ & $29,488(25.3)$ & $310,454(3.5)$ & $<.0001$ & $5414(0.1)$ \\
\hline Mother's Age Category (years) & & & & $<.0001$ & \\
\hline$<20$ & $691,055(7.6)$ & $13,310(11.4)$ & $677,745(7.6)$ & & \\
\hline $20-24$ & $2,096,978(23.2)$ & $31,111(26.7)$ & $2,065,867(23.2)$ & & \\
\hline $25-29$ & $2,614,045(28.9)$ & $33,249(28.5)$ & $2,580,796(28.9)$ & & \\
\hline $30-34$ & $2,328,649(25.8)$ & $26,609(22.8)$ & $2,302,040(25.8)$ & & \\
\hline $35-39$ & $1,056,573(11.7)$ & $10,137(8.7)$ & $1,046,436(11.7)$ & & \\
\hline$>=40$ & $247,128(2.7)$ & $2211(1.9)$ & $244,917(2.7)$ & & \\
\hline Pre-pregnancy Body Mass Index $\left(\mathrm{kg} / \mathrm{m}^{2}\right)$ & & & & $<.0001$ & $36,428(4)$ \\
\hline Underweight $<18.5$ & $330,184(3.7)$ & $4023(3.4)$ & $326,161(3.7)$ & & \\
\hline Normal 18.5-24.9 & $4,101,894(45.4)$ & $57,298(49.1)$ & $4,044,596(45.4)$ & & \\
\hline Overweight 25.0-29.9 & $2,209,657(24.5)$ & $29,045(24.9)$ & $2,180,612(24.5)$ & & \\
\hline Obesity | 30.0-34.9 & $1,141,225(12.6)$ & $13,188(11.3)$ & $1,128,037(12.6)$ & & \\
\hline Obesity || 35.0-39.9 & $530,684(5.9)$ & $5453(4.7)$ & $525,231(5.9)$ & & \\
\hline Extreme Obesity $\| I \mid>=40$ & $356,516(3.9)$ & $3263(2.8)$ & $353,253(4.0)$ & & \\
\hline Mother's Education & & & & $<.0001$ & $101,440(1.1)$ \\
\hline Primary / High School & $1,489,421(16.5)$ & $16,434(14.1)$ & $1,472,987(16.5)$ & & \\
\hline Undergraduate & $4,108,603(45.5)$ & $52,287(44.8)$ & $4,056,316(45.5)$ & & \\
\hline Academic Degree & $2,392,987(26.5)$ & $32,652(28.0)$ & $2,360,335(26.5)$ & & \\
\hline Doctorate or Professional Degree & $941,977(10.4)$ & $13,867(11.9)$ & $928,110(10.4)$ & & \\
\hline Marital Status & $5,436,538(60.2)$ & $64,979(55.7)$ & $5,371,559(60.2)$ & $<.0001$ & \\
\hline Mother's Race & & & & $<.0001$ & \\
\hline White & $6,988,814(77.4)$ & $83,482(71.6)$ & $6,905,332(77.4)$ & & \\
\hline Black & $1,353,358(15.0)$ & $17,532(15.0)$ & $1,335,826(15.0)$ & & \\
\hline American Indian / Alaskan Native & $93,982(1.0)$ & $1058(0.9)$ & $92,924(1.0)$ & & \\
\hline Asian / Pacific Islander & $598,274(6.6)$ & $14,555(12.5)$ & $583,719(6.5)$ & & \\
\hline Resident Status & $6,627,740(73.4)$ & $87,787(75.3)$ & $6,539,953(73.3)$ & $<.0001$ & \\
\hline Nulliparous & $3,639,997(40.3)$ & $94,060(80.7)$ & $3,545,937(39.8)$ & $<.0001$ & $389,941(4.3)$ \\
\hline Smoker & $718,229(7.9)$ & $5415(4.6)$ & $712,814(8.0)$ & $<0.001$ & $511,070(5.7)$ \\
\hline Chronic Hypertension & $112,002(1.2)$ & $1440(1.2)$ & $110,562(1.2)$ & 0.8660 & $9224(0.1)$ \\
\hline Pregnancy Associated Hypertension & $349,609(3.9)$ & $6802(5.8)$ & $342,807(3.8)$ & $<.0001$ & $9224(0.1)$ \\
\hline Diabetes (overall) & $494,901(5.5)$ & $7103(6.1)$ & $487,798(5.5)$ & $<.0001$ & $9224(0.1)$ \\
\hline Pre-pregnancy Diabetes & $57,013(0.6)$ & $685(0.6)$ & $56,328(0.6)$ & 0.0566 & $9224(0.1)$ \\
\hline Gestational Diabetes & $437,888(4.8)$ & $6418(5.5)$ & $431,470(4.8)$ & $<.0001$ & $9224(0.1)$ \\
\hline Month Prenatal Care Began & & & & $<.0001$ & $300,509(3.3)$ \\
\hline 1st to 3rd month & $6,474,810(71.7)$ & $85,726(73.5)$ & $6,389,084(71.6)$ & & \\
\hline 4th to 6th month & $1,744,616(19.3)$ & $21,724(18.6)$ & $1,722,892(19.3)$ & & \\
\hline 7th to final month & $408,509(4.5)$ & $5174(4.4)$ & $403,335(4.5)$ & & \\
\hline No prenatal care & $105,984(1.2)$ & $948(0.8)$ & $105,036(1.2)$ & & \\
\hline Meconium-stained amniotic fluid & $491,605(5.4)$ & $20,313(17.4)$ & $471,292(5.3)$ & $<.0001$ & \\
\hline
\end{tabular}


Table 1 Demographics and Characteristics of Mothers and Babies Stratified by Chorioamnionitis - n\% (Continued)

\begin{tabular}{|c|c|c|c|c|c|}
\hline Characteristic & $\begin{array}{l}\text { Total } \\
(\boldsymbol{N}=9,034,428)\end{array}$ & $\begin{array}{l}\text { Chorioamnionitis } \\
(\boldsymbol{N}=116,627)\end{array}$ & No chorioamnionitis $(\boldsymbol{N}=8,917,801)$ & $\boldsymbol{p}$-Value & Unknown \\
\hline Tocolysis & $55,479(0.6)$ & $1281(1.1)$ & $54,198(0.6)$ & $<.0001$ & $13,226(0.1)$ \\
\hline Induction of Labor & $2,221,042(24.6)$ & $37,531(32.2)$ & $2,183,511(24.5)$ & $<.0001$ & \\
\hline Final Route and Method of Delivery & & & & $<.0001$ & $4106(0.0)$ \\
\hline Spontaneous & $5,976,036(66.1)$ & $61,161(52.4)$ & $5,914,875(66.3)$ & & \\
\hline Forceps & $58,786(0.7)$ & $2529(2.2)$ & $56,257(0.6)$ & & \\
\hline Vacuum & $270,410(3.0)$ & $8732(7.5)$ & $261,678(2.9)$ & & \\
\hline Cesarean & $2,725,090(30.2)$ & $44,186(37.9)$ & $2,680,904(30.1)$ & & \\
\hline Gestational Age (weeks) & & & & $<.0001$ & \\
\hline 37 & $825,690(9.1)$ & $7647(6.6)$ & $818,043(9.2)$ & & \\
\hline 38 & $1,667,050(18.5)$ & $16,174(13.9)$ & $1,650,876(18.5)$ & & \\
\hline 39 & $3,078,494(34.1)$ & $32,304(27.7)$ & $3,046,190(34.2)$ & & \\
\hline 40 & $2,025,919(22.4)$ & $33,690(28.9)$ & $1,992,229(22.3)$ & & \\
\hline 41 and over & $1,437,275(15.9)$ & $26,812(23.0)$ & $1,410,463(15.8)$ & & \\
\hline Birth Weight Category (g) & & & & $<.0001$ & \\
\hline$<2500$ & $237,523(2.6)$ & $1740(1.5)$ & $235,783(2.6)$ & & \\
\hline 2500-3999 & $7,994,850(88.5)$ & $101,877(87.4)$ & $7,892,973(88.5)$ & & \\
\hline$>4000$ & $802,055(8.9)$ & $13,010(11.2)$ & $789,045(8.8)$ & & \\
\hline Sex of Infant & & & & $<.0001$ & \\
\hline Female & $4,434,570(49.1)$ & $55,583(47.7)$ & $4,378,987(49.1)$ & & \\
\hline Male & $4,599,858(50.9)$ & $61,044(52.3)$ & $4,538,814(50.9)$ & & \\
\hline
\end{tabular}

lower than 0.2 were considered for the next step. Any variable with an odds ratio (OR) lower than 1.3 was deemed to have a weak association with the outcome and was therefore discarded for the multivariate analysis. In addition, interactions with strong to moderate importance were the only ones kept for the multivariate analysis in each final model (change in any parameter estimate greater than $20 \%$ ).

For the multivariate analysis, similar variables were grouped together to build intermediate models. Variables were dropped if the $p$-value became higher than 0.05 . Finally, variables from the intermediate models were sequentially combined together, and those with a p-value smaller than 0.05 were kept to obtain the final model. 95\% confidence intervals (CI) were computer for adjusted OR. This analysis included only women with complete data.

All of the analyses were conducted using SAS 9.4 software (SAS Institute Inc. Cary, NC, USA).

This study was approved by the CHU Sainte-Justine ethics committee.

\section{Results}

Among 11,862,782 live births, 9,034,428 were included, among which 116,627 (1.29\%) had documented chorioamionitis (95\% confidence interval (CI): 1.28-1.30\%, Fig. 1). Details on demographics and risk factors by chorioamnionitis status are presented in Table 1. The number of neonatal deaths and early neonatal deaths were respectively $106(0.09 \%)$ and $71(0.06 \%)$ in the chorioamnionitis group versus $5688(0.06 \%)$ and 3320 $(0.04 \%)$ in the no chorioamnionitis group $(p=0.0003$ and $<0.0001)$. The crude odds ratio for the association between chorioamnionitis and neonatal mortality was 1.42 (95\% CI: $1.18-1.73$ ).

The odds ratios from the final models are presented in Figs. 2 and 3. Smoking was significantly associated with early neonatal death in the context of chorioamnionitis (OR 2.36, 95\% CI: 1.11-5.01) but was not associated in the absence of chorioamnionitis (OR 0.93, 95\% CI:0.821.05). For neonatal death, the impact of gestational age (37 weeks compared to 39 weeks) was more important in the context of chorioamnionitis $(\mathrm{OR}=3.19,95 \% \mathrm{CI}$ : 1.75-5.82 versus 1.63, 95\% CI: $1.49-1.79)$. Same wise, the impact of smoking on the risk of neonatal death was higher in the context of chorioamnionitis (OR 2.44, 95\% CI:1.34-4.43 versus 1.24, 95\% CI:1.14-1.35).

The main risk factors for early neonatal death were maternal age over 40 (OR 1.75. 95\% CI:1.45-2.11), obesity (OR 1.62, 95\% CI:1.38-1.90), late or no prenatal care (OR 3.6, 95\% CI:2.97-4.39), all gestational ages other than 39 weeks $(37,38,40$ and 41, (OR 1.7, 1.2, 1.2 and 1.53 respectively), delivery by c-section (OR 2.12, 95\% 


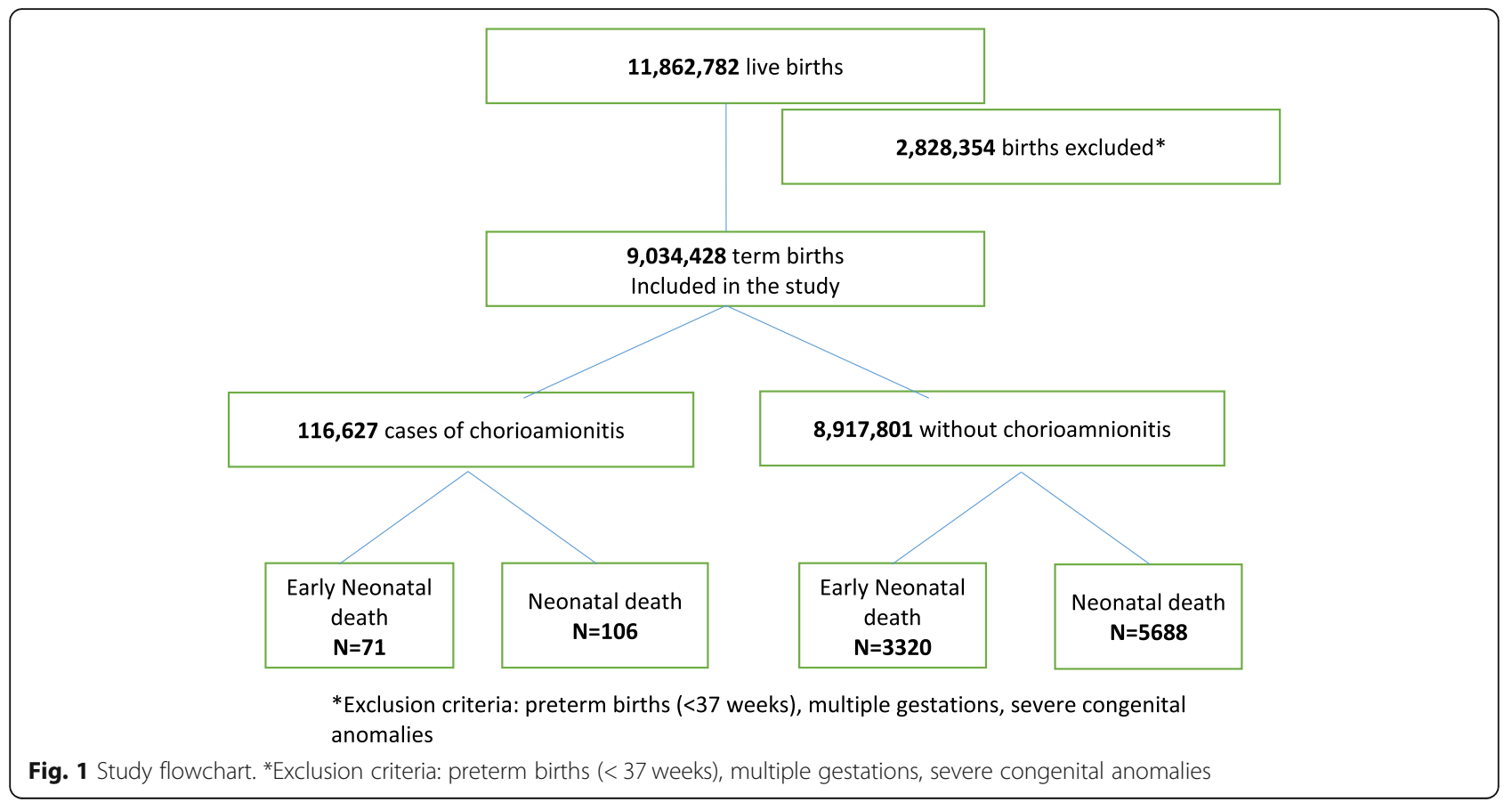

CI:1.96-2.30), vacuum (OR 1.43, 95\% CI: 1.14-1.80), meconium-stained amniotic fluid (OR 2.19, 95\% CI: 1.93-2.48) and birth weight < $2500 \mathrm{~g}$ (OR 11.64, 95\% CI: 9.85-13.76). Finally, Induction of labor was associated with a decreased risk of early neonatal death with an OR of 0.82 (95\% CI 0.75-0.91).

The main risk factors for neonatal death were extremes of maternal age: $<20$ and $>40$ (OR 1.24, 95\% CI: $1.11-1.39$ and $1.49,95 \% \mathrm{CI}: 1.28-1.74$ respectively), late or no prenatal care (OR 3.26, 95\% CI: 2.80-3.80), diabetes (OR 1.78, 95\% CI:1.41-2.24), meconium-stained amniotic fluid (OR 1.87, 95\% CI: 1.7-2.07), delivery by c-section (OR 1.89, 95\% CI: 1.78-2.01), vaccum (OR 1.27, 95\% CI: 1.06-1.51) and birth weight $<2500 \mathrm{~g}(\mathrm{OR}=$ 9.66, 95\% CI: 8.43-11.06).

\section{Discussion}

In this population based retrospective cohort, a significant positive interaction was found between gestational age and smoking on the one hand and chorioamnionitis on the other hand as risk factors for neonatal death and early neonatal death, controlling for other risk factors.

The increased risk of neonatal morbidity and death associated with chorioamnionitis has previously been reported for term deliveries [4, 5]. Consistently, the severity of the maternal and more importantly the fetal inflammatory response has been associated with increased neonatal mortality and morbidity [6]. In a study realized on $2008 \mathrm{CDC}$ public files, the adjusted OR of chorioamnionitis for neonatal death was 1.72 , 95\% CI $1.20-2.45$, but the interaction between chorioamnionitis and other risk factors for neonatal death were not tested [4].

Smoking has previously been reported as a risk factor for perinatal mortality [7]. The interaction of smoking with chorioamnionitis controlling for birth weight that our study has revealed could be caused by the impact of tobacco exposure on the neonatal ability to overcome infection and inflammation that is associated with chorioamnionitis. Indeed, immunity is decreased in children of mothers who smoked during pregnancy as early as in the neonatal period [8-10].

Also, it is of note that in our study, smokers had a lower risk of developing chorioamnionitis. The decrease in immune response induced by smoking could lead to differ the onset of clinical symptoms of chorioamnionitis, which could explain a lower frequency of clinically diagnosed chorioamnionitis and subsequently less treatment and more adverse outcomes in newborns.

Early term deliveries have been previously demonstrated to be associated with worse neonatal outcomes than full term deliveries ( $\geq 39$ weeks) [11]. Similarly, the association between post-term deliveries and perinatal death has been established in Swedish, English and US population based cohort studies [7, 12-15] as well as in a systematic review [15]. The positive interaction between chorioamnionitis and gestational age, found in our study even if preterm deliveries were excluded, could be explained by increased lung and brain susceptibility at gestational age less than 39 weeks.

The lack of interaction between meconium-stained amniotic fluid and chorioamnionitis is surprising as 


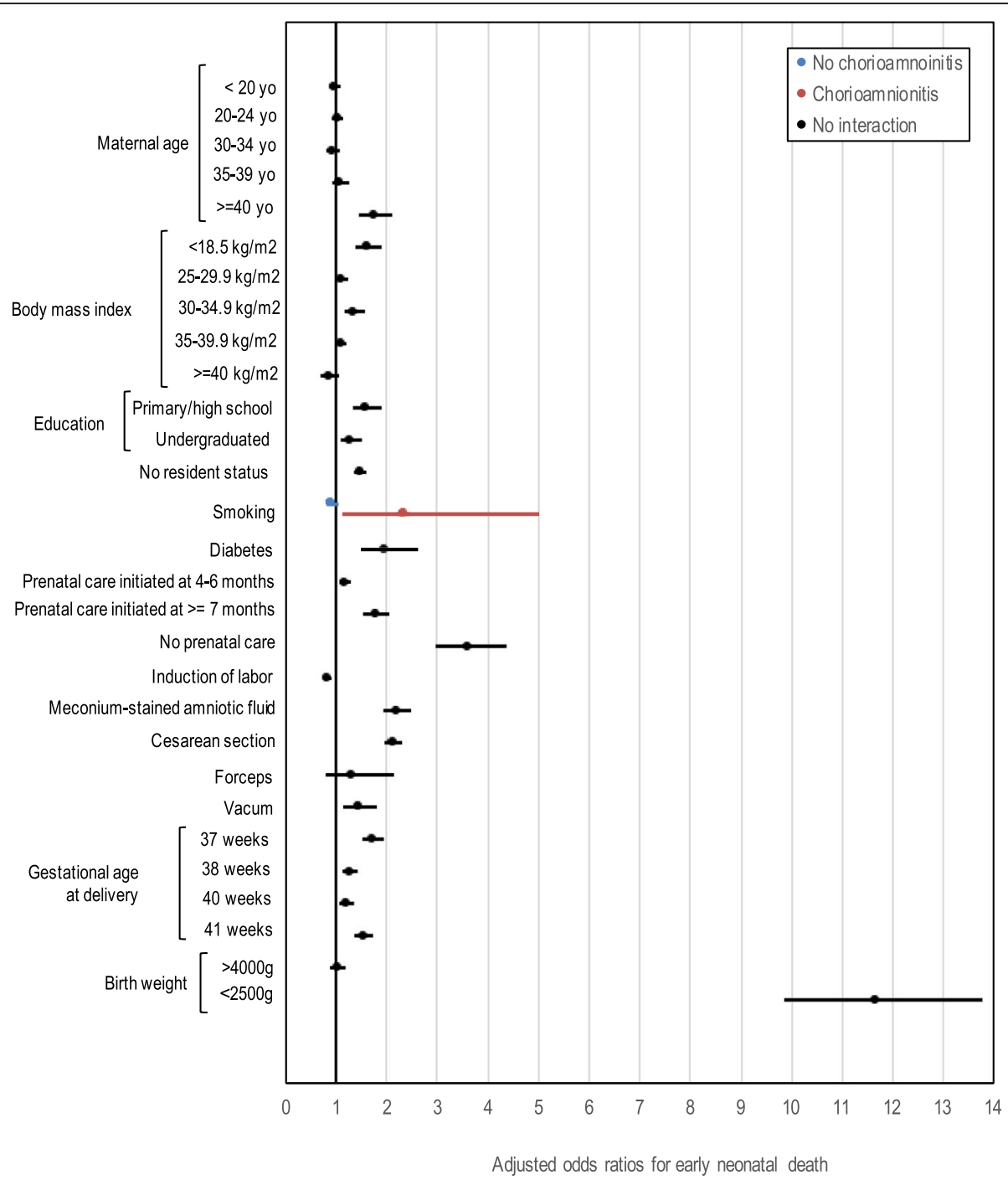

Fig. 2 Forest plot, Adjusted odds Ratios for Early neonatal death. Birth weight reference group: 2500-2999 g. Gestational age reference group: 39 weeks. Prenatal care reference group: 1st-3rd month of gestation. Maternal age reference group: 25-29years old. BMl reference group: 18-24.9 $\mathrm{kg} / \mathrm{m}^{2}$. Education reference group: doctorate/professional degree

chorioamnionitis has been reported as a risk factor for meconium aspiration syndrome [5]. Other significant risk factors identified in this study were consistent with previous publications. The association of adverse perinatal outcomes with late prenatal care and lower maternal education have been reported in earlier analyses of the CDC public files [16] and in other settings [17]. Similarly, severe obesity has been consistently associated with adverse perinatal outcomes [18-20].

Lastly, induction of labor was associated with a significant decrease in neonatal mortality in our study, like it has been inconsistently reported in observational studies [21] as well as in randomized control trials [22, 23]. This association should be considered with caution as the indication for labor induction could not be taken into account in our analyses. The vacuum or cesarean delivery- increased risk of early mortality was likely not causal as obstetrical intervention is expected in cases of suspected fetal asphyxia.

The main strength of our study is that it is a population-based analysis with large number outcomes. It is the first study aimed at exploring maternal and fetal risk factors at term for neonatal death and their interaction with chorioamnionitis. Limitations of this study should be noted. First, it is a retrospective study therefore causality cannot be assumed. For this reason, prospective observational studies should be conducted. Moreover, our results are based on 2010-2013 data, because these were the years with the most complete infant mortality information that were publicly available. However, the criteria for the clinical diagnosis of chorioamnionitis have been reviewed since [24]. Furthermore, as we were using a public bank, 


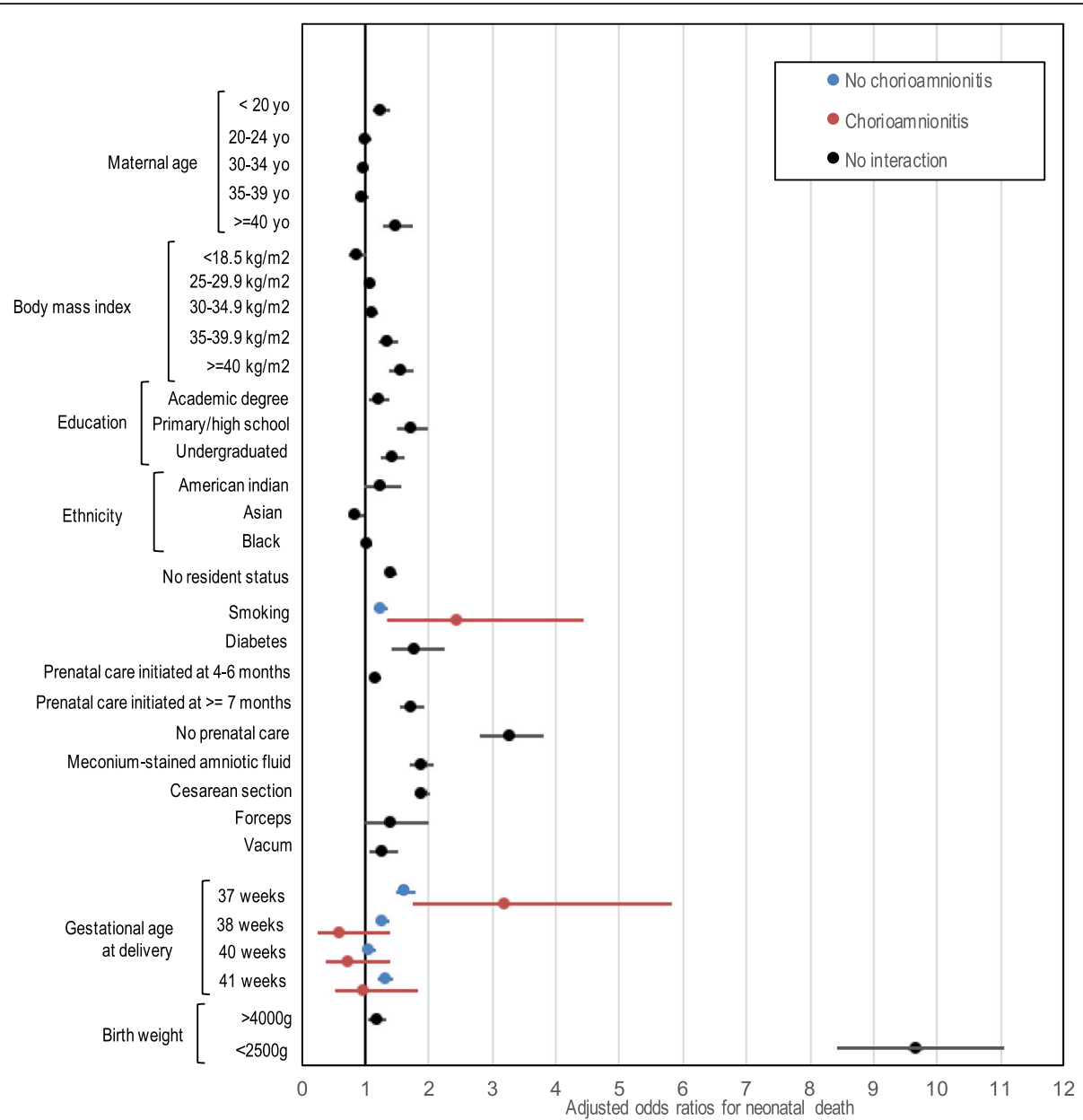

Fig. 3 Forest plot, Adjusted odds ratios for neonatal death. Gestational age reference group: 39 weeks. Birth weight reference group: $2500-2999 \mathrm{~g}$. Prenatal care reference group: 1st-3rd month of gestation. Maternal age reference group: $25-29$ years old. BMl reference group: $18-24.9 \mathrm{~kg} / \mathrm{m}^{2}$. Education reference group: doctorate/professional degree. Ethnicity reference group: white

the details on chorioamnionitis diagnostic criteria, method used for gestational age determination, treatment of chorioamnionitis and neonatal management were not available. The cause of death was also not accessible, which could have provided additional information on associations identified in the study. The proportion of women with missing data which were not included in the multivariate analysis is approximately $15 \%$. Although this may seem elevated, it is not believed to be a limitation as it is not due to recall or selection bias-and there was no difference in the amount of missing data between the two groups. Lastly, the analyses did not include intra-uterine fetal demise which may have falsely diminished the incidence and impact of chorioamnionitis.

\section{Conclusions}

Smoking as well as early term have a positive interaction with chorioamnionitis for the risk of neonatal mortality controlling for other risk factors. This should be taken into account when counseling pregnant women. Smoking cessation is an important adjunct to routine obstetrical care and the risks associated should be discussed during prenatal visits. It should also be considered when managing laboring pregnant women with diagnosis of chorioamnionitis, particularly if they are early term. Preventative measures to minimize development of chorioamnionitis during labor could include less vaginal exams and aiming for shorter labor. Neonatology should also be made aware of the presence of these risk factors and their known association with neonatal mortality in babies born to a mother with chorioamnionitis.

Abbreviations

CDC: Centers for Disease Control and Prevention; Cl: Confidence interval; OR: Odds ratio

Acknowledgements Not applicable. 


\section{Authors' contributions}

DZ wrote the research protocol and drafted the manuscript. GG and JB designed the analyses plan and performed the statistical analysis of the data and were a major contributor in writing the manuscript. MB and AMN provided their expertise in neonatology for the interpretation of the results. IB supervised the design of the study and the analyses as well as interpretation of the results. All authors read and approved the final manuscript.

\section{Funding}

IB is the recipients of salary award (chercheur-boursier) from FRQ-S (Fonds de Recherche du Québec-Santé). Funding for this project was provided by the department of obstetrics and gynecology of the Université de Montréal (Canada). The funder was not involved in the design of the study and collection, analysis, and interpretation of data and in writing the manuscript.

\section{Availability of data and materials}

The dataset analyzed during the current study is publicly available in the US Centers for Disease Control and Prevention 2010-2013 birth/infant death public files (https://www.cdc.gov/nchs/nvss/linked-birth.htm).

\section{Ethics approval and consent to participate}

This study was approved by the CHU Sainte-Justine ethics committee.

\section{Consent for publication}

Not applicable.

\section{Competing interests}

The authors declare that they have no competing interests.

\section{Author details}

'Department of Obstetrics and Gynecology, Faculty of Medicine, Université de Montréal, 3175 Côte Sainte-Catherine, Montreal, QC H3T 1C5, Canada. ${ }^{2}$ Department of Obstetrics and Gynecology, McGill University Health Centre (MUHC), McGill University, Montreal, Canada. ${ }^{3}$ Department of Pediatrics, Montreal Children's Hospital, McGill University Health Centre, Montreal, QC, Canada. ${ }^{4}$ Applied Clinical Research Unit (URCA), Centre de recherche du CHU Sainte-Justine, Montreal, QC, Canada. ${ }^{5}$ Department of Pediatrics, Faculty of Medicine, Université de Montréal, Montreal, QC, Canada. ${ }^{6} \mathrm{CHU}$ Sainte-Justine Research Centre, Montreal, QC, Canada. ${ }^{7}$ Department of Social and Preventive Medicine, Faculty of Medicine, Université de Montréal, Montreal, QC, Canada.

Received: 8 November 2019 Accepted: 28 July 2020

Published online: 08 August 2020

\section{References}

1. Tita AT, Andrews WW. Diagnosis and management of clinical chorioamnionitis. Clin Perinatol. 2010;37(2):339-54.

2. Gibbs RS, Dinsmoor MJ, Newton ER, Ramamurthy RS. A randomized trial of intrapartum versus immediate postpartum treatment of women with intraamniotic infection. Obstet Gynecol. 1988;72(6):823-8.

3. Venkatesh KK, Jackson W, Hughes BL, Laughon MM, Thorp JM, Stamilio DM, et al. Association of chorioamnionitis and its duration with neonatal morbidity and mortality. J Perinatol. 2019;39(5):673-82.

4. Malloy $\mathrm{MH}$. Chorioamnionitis: epidemiology of newborn management and outcome United States 2008. J Perinatol: official journal of the California Perinatal Association. 2014;34(8):611-5.

5. Alexander JM, Mclntire DM, Leveno KJ. Chorioamnionitis and the prognosis for term infants. Obstet Gynecol. 1999;94(2):274-8.

6. Lau J, Magee F, Qiu Z, Houbé J, Von Dadelszen P, Lee SK. Chorioamnionitis with a fetal inflammatory response is associated with higher neonatal mortality, morbidity, and resource use than chorioamnionitis displaying a maternal inflammatory response only. Am J Obstet Gynecol. 2005;193(3): 708-13

7. Platt RW, Joseph KS, Ananth CV, Grondines J, Abrahamowicz M, Kramer MS. A proportional hazards model with time-dependent covariates and timevarying effects for analysis of fetal and infant death. Am J Epidemiol. 2004; 160(3):199-206.
8. Chahal N, McLain AC, Ghassabian A, Michels KA, Bell EM, Lawrence DA, et al Maternal smoking and newborn cytokine and immunoglobulin levels. Nicotine Tobacco Res. 2017;19(7):789-96.

9. Metzger MJ, Halperin AC, Manhart LE, Hawes SE. Association of maternal smoking during pregnancy with infant hospitalization and mortality due to infectious diseases. Pediatr Infect Dis J. 2013;32(1):e1-7.

10. Noakes PS, Hale J, Thomas R, Lane C, Devadason SG, Prescott SL. Maternal smoking is associated with impaired neonatal toll-like-receptor-mediated immune responses. Eur Respir J. 2006;28(4):721-9.

11. Parikh LI, Reddy UM, Männistö T, Mendola P, Sjaarda L, Hinkle S, et al. Neonatal outcomes in early term birth. Am J Obstet Gynecol. 2014;211(3): 265.e1-e11.

12. Divon MY, Haglund B, Nisell H, Otterblad PO, Westgren M. Fetal and neonatal mortality in the postterm pregnancy: the impact of gestational age and fetal growth restriction. Am J Obstet Gynecol. 1998;178(4):726-31.

13. Hilder L, Costeloe K, Thilaganathan B. Prolonged pregnancy: evaluating gestation-specific risks of fetal and infant mortality. Br J Obstet Gynaecol. 1998;105(2):169-73.

14. Ingemarsson I, Kallen K. Stillbirths and rate of neonatal deaths in 76,761 postterm pregnancies in Sweden, 1982-1991: a register study. Acta Obstet Gynecol Scand. 1997;76(7):658-62.

15. Muglu J, Rather H, Arroyo-Manzano D, Bhattacharya S, Balchin I, Khalil A et al. Risks of stillbirth and neonatal death with advancing gestation at term: a systematic review and meta-analysis of cohort studies of 15 million pregnancies. PLoS Med. 2019;16(7):e1002838.

16. Partridge S, Balayla J, Holcroft CA, Abenhaim HA. Inadequate prenatal care utilization and risks of infant mortality and poor birth outcome: a retrospective analysis of $28,729,765$ U.S. deliveries over 8 years. Am J Perinatol. 2012;29(10):787-93.

17. Raatikainen K, Heiskanen N, Heinonen S. Under-attending free antenatal care is associated with adverse pregnancy outcomes. BMC Public Health. 2007;7:268.

18. McCall SJ, Li Z, Kurinczuk JJ, Sullivan E, Knight M. Maternal and perinatal outcomes in pregnant women with BMI >50: an international collaborative study. PLoS One. 2019;14(2):e0211278.

19. Sullivan EA, Dickinson JE, Vaughan GA, Peek MJ, Ellwood D, Homer CS, et al. Maternal super-obesity and perinatal outcomes in Australia: a national population-based cohort study. BMC Pregnancy Childbirth. 2015;15:322.

20. Crane JM, Murphy P, Burrage L, Hutchens D. Maternal and perinatal outcomes of extreme obesity in pregnancy. J Obstet Gynaecol Can. 2013; 35(7):606-11.

21. Grobman WA, Caughey AB. Elective induction of labor at 39 weeks compared with expectant management: a meta-analysis of cohort studies. Am J Obstet Gynecol. 2019.

22. Grobman WA, Rice MM, Reddy UM, Tita ATN, Silver RM, Mallett G, et al. Labor induction versus expectant Management in low-Risk Nulliparous Women. N Engl J Med. 2018;379(6):513-23.

23. Walker KF, Bugg GJ, Macpherson M, McCormick C, Grace N, Wildsmith C, et al. Randomized trial of labor induction in women 35 years of age or older. N Engl J Med. 2016;374(9):813-22.

24. American College of Obstetricians and Gynecologists. Intrapartum management of intraamniotic infection. Committee opinion $\mathrm{N}^{\circ} 712$. Obstet Gynecol. 2017;130:e95-101.

\section{Publisher's Note}

Springer Nature remains neutral with regard to jurisdictional claims in published maps and institutional affiliations.

Ready to submit your research? Choose BMC and benefit from:

- fast, convenient online submission

- thorough peer review by experienced researchers in your field

- rapid publication on acceptance

- support for research data, including large and complex data types

- gold Open Access which fosters wider collaboration and increased citations

- maximum visibility for your research: over $100 \mathrm{M}$ website views per year

At $\mathrm{BMC}$, research is always in progress.

Learn more biomedcentral.com/submissions 